\title{
ARtritis PSORIASICA MUtilante En Miembro INFERIOR
}

\author{
Psoriatic Arthritis Mutilans in Lower Limb
}

Sebastian Legua-Perez ${ }^{1}$

Daciente masculino de 55 años de edad con diagnóstico de psoriasis hace 15 años, comenzó a presentar características mutilantes en miembro inferior izquierdo, por lo que se realizan los estudios correspondientes y se llega al diagnostico de artritis psoriasica mutilante, se trató con agente biológico Anti TNF, infliximab, monerreno hace 6 años, es ingresado por urgencias luego de presentar perdida del conocimiento y disartria.

Al examen se aprecia placas que se descaman finamente en frente, dorso y extremidades (Figura 1), además incapacidad funcional, deformidad articular de pie izquierdo, acompañado de onicolisis y poliartralgias (Figura 2).

La artritis psoriasica (AP) es una enfermedad inflamatoria crónica del sistema musculo - esquelético que provoca también lesiones extraarticulares, siendo requisito indispensable para el diagnostico que sea seronegativa, es decir que no presente factor reumatoideo positivo, la AP presenta 5 patrones clínicos, que son: Poliartritis Simetrica, Oligoartritis Asimetrica, Artritis a predominio de articulación interfalangica distal, espondilitis y artritis mutilans ${ }^{1}$.

La AP mutilans es la más rara y grave de las 5 formas de presentación, Moll y Wright describieron en 1973 que afectaba aproximadamente al 5\% de los pacientes que presentan $\mathrm{AP}^{2}{ }^{2}$, pero algunos estudios mencionan una prevalencia de la forma mutilans que varía entre $2-21 \%$ en pacientes con AP ${ }^{3}$. La clínica, cursa con destrucción articular severa acompañada de incapacidad funcional, poliartralgias, destrucción de las uñas, lesiones dérmicas tales como placas descamativas pruriginosas ${ }^{3}$.

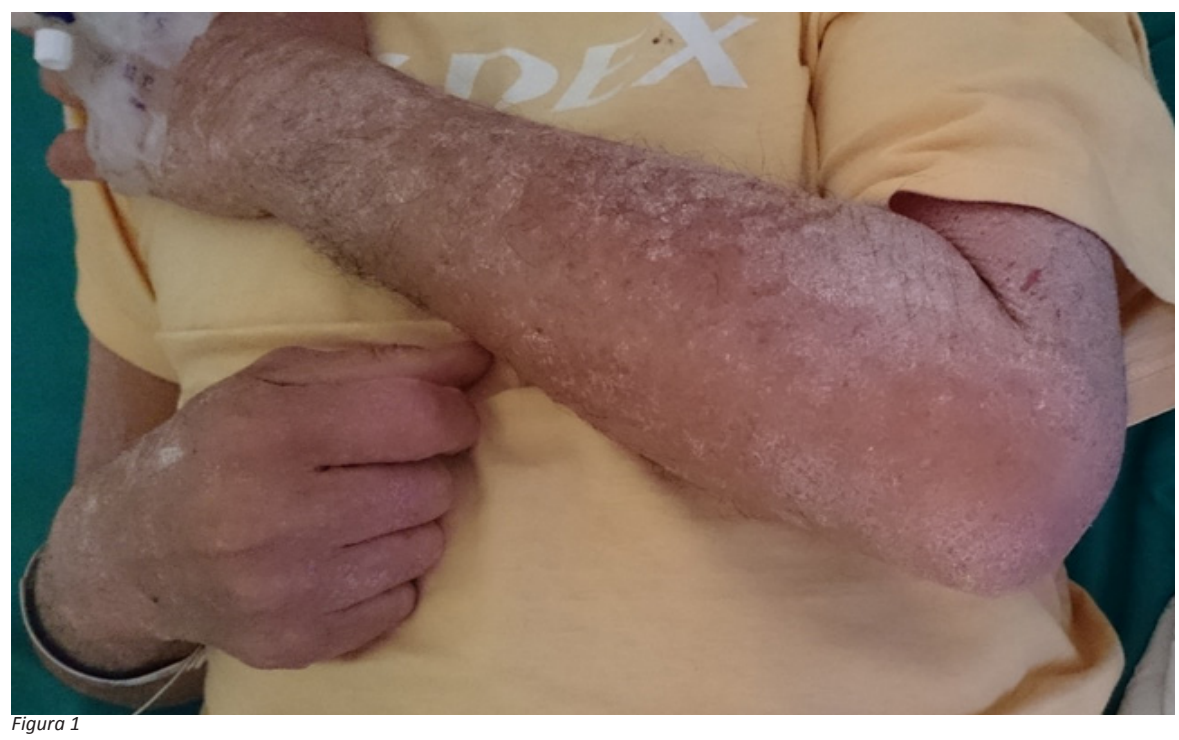

Facultad de Medicina Humana "Daniel Alcides Carrión", Ica - Perú

Correspondencia a: leguasebastian@gmail.com

Palabras clave: Artritis, mutilante, miembro inferior.

Keywords: Arthritis, mutilating, lower limb.

\footnotetext{
Procedencia y arbitraje: no comisionado, sometido a arbitraje externo.

Recibido para publicación: 10 de Marzo del 2017 Aceptado para publicación: 21 de junio del 2017 
El diagnostico se basa principalmente en la clínica y los antecedentes, se ayuda de exámenes de laboratorio y sobretodo exámenes radiológicos tales como radiografia y resonancia magnética ${ }^{3}$.

El tratamiento inicial cursa con analgésicos y antiinflamarios, en caso progrese la enfermedad se recomienda metrotexate, sulfazalacina o ciclosporina, dejando como última opción el uso de agentes biológicos tales como etanercept, golimumab, infliximab o apremilast. ${ }^{4}$

\section{REFERENCIAS}

1.Jadon DR, Shaddick G, Tillett W, Korendowych E, Robinson G, Waldron N, et al. Psoriatic Arthritis Mutilans: Characteristics and Natural Radiographic History. J Rheumatol [Internet]. 2015; 42(7): 1169-76. Disponible en: http://www.jrheum.org/ content/42/7/1169.full

2. Moll JM, Wright V. Psoriatic Arthritis. Seminars in Arthritis and Rheumatism [Internet].1973; 3(1): 55-78. Disponible en: http://www.semarthritisrheumatism.com/ article/0049-0172(73)90035-8/pdf

3. Haddad A, Johnson SR, Somaily M, Fazelzad R, Kron AT, Chau C, et al. Psoriatic Arthritis Mutilans: Clinical and Radiographic Criteria. A Systematic Review. J Rheumatol [Internet]. 2015; 42(8):1432-38. Disponible en: https://doi. org/10.3899/jrheum.141545

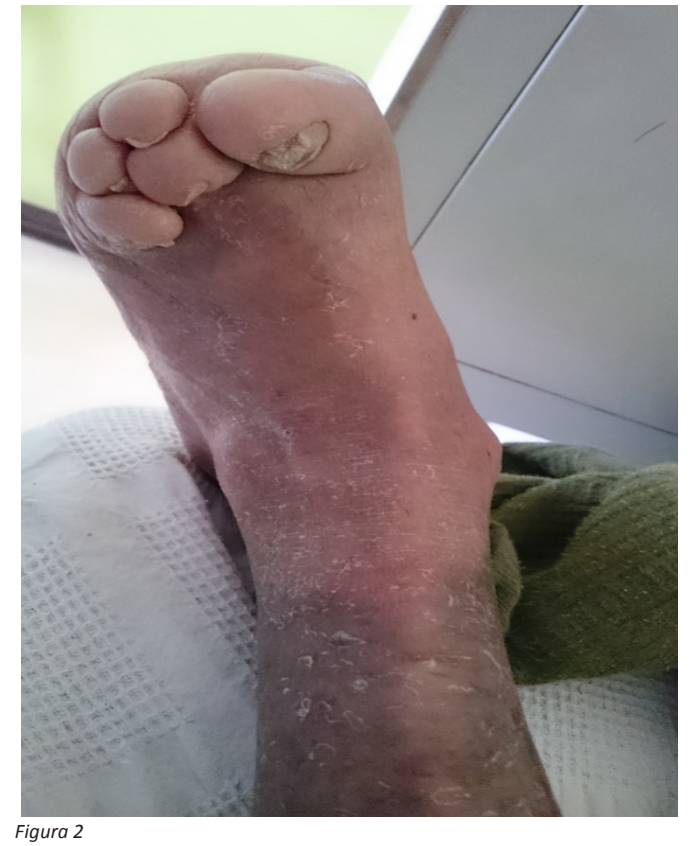

4. Gossec L, Smolen JS, Ramiro S, Wit M, Cutolo M, Dougados M, et al. European League Against Rheumatism (EULAR) recommendations for the management of psoriatic arthritis with pharmacological therapies: 2015 update. Ann Rheum Dis [Internet]. 2016; 75:499-510. Disponible en: http://ard.bmj.com/content/75/3/499 